\title{
Assessment of clients satisfaction with outpatient services at Yekatit 12 Hospital Medical College, Addis Ababa, Ethiopia
}

\author{
Tirhas T. Berehe ${ }^{1 *}$, Getabalew E. Bekele ${ }^{1}$, Yimer S. Yimer ${ }^{2}$ and Taye Z. Lozza ${ }^{1}$
}

\begin{abstract}
Objective: This study aimed at assessing clients' satisfaction and associated factors among adults. A cross sectional facility based study was conducted on 420 clients of Yekatit 12 Hospital Medical College from 1 June 2016 to 1 July 2016. Data was entered, cleaned, and analyzed using SPSS statistical package. Data was analyzed using a multivariable logistic regression model to find out the most significant predictors for clients satisfaction with outpatient services at Yekatit 12 Hospital Medical College.

Results: This study showed that the overall clients' satisfaction level towards out-patient health service at Yekatit 12 Hospital Medical College was $47 \%$ at $95 \% \mathrm{Cl}(42.5,51.7 \%)$. The most frequently identified problems were: lack of clean toilet in nearby the waiting areas, lack of waiting area particularly at pharmacy, inadequate furniture like chair, lack of adequate drugs and supplies, lack of privacy at the examination room, lack of direction signs, and poor communication between clients and health service providers. In conclusion the overall satisfaction level of the patients is low, so this demands the Hospital to take further action on the identified problems to improve the services delivered to the patients.
\end{abstract}

Keywords: Patient satisfaction, Outpatient, Yekatit 12 Hospital Medical College

\section{Introduction}

Increasing awareness on healthcare service brings increased utilization of healthcare. Evidence of variations in satisfaction with clinical practices in many health service institutions in Ethiopia have raised interest in measuring and improving healthcare service to enhance customer satisfaction [1]. According to the Donabedian model [2], three interrelated key domains namely structure, process, and outcome are important for identifying clients' satisfaction which is by far an important indicator of service quality $[2,3]$. Therefore, client satisfaction has been found to be the most useful tool for getting clients' views on how to provide health care service. Generally, clients are the best source of information on both quality and quantity of health care services. Moreover, clients'

\footnotetext{
*Correspondence: ttrhas@gmail.com

${ }^{1}$ Department of Public Health, College of Medicine, Yekatit 12 Hospitals, Addis Ababa, Ethiopia

Full list of author information is available at the end of the article
}

views provide useful information that can be used in planning and providing improved health care service [4].

But client perception about care is neglected area by many health managers and clinicians in developing countries [5]. Taking this into consideration, the study aimed at determining the level of clients' satisfaction towards out-patient service at Yekatit 12 Hospital Medical College Addis Ababa Ethiopia. The result from this study identifies the problems, which can be used to improving health service delivery through informed strategies.

\section{Main text \\ Methods}

This study was conducted at Yekatit 12 Hospital Medical College (Y12HMC) outpatient department from 1 June 2016 to 1 July 2016. The specialized hospital is found in Addis Ababa, the capital city of Ethiopia. It is serving more than 5 million people in the catchment area (see Additional file 1). Quantitative approaches were applied in the study. All clients visiting the hospital for outpatient 
health services from 1 June 2016 to 1 July 2016 were the source population and clients coming to the outpatient departments during the study period were selected using the systematic random sampling technique was the study population. The exclusion criteria for this study were; the very seriously ill clients who did not have somebody to accompany them because of the difficulty of interviewing such cases (getting the consent, lack of tolerance of the pain or illness and etc.), and clients coming for the second time during the study period and children who are under 15 who are alone. Quantitative approaches were applied in the study. The sample size was 423 which were determined using one population proportion formula. A systematic random sampling method using patients' registration number as a sampling frame was employed to select respondents (see Additional file 2).

To collect relevant data, structured questionnaire was developed through reviewing related literature for the study [6-9]. Then, the validity of the questionnaire was tested after translating in to Amharic language. The lexical equivalence of questionnaire was examined after back translation. Content validity was established by a panel of experts from public health, community medicine, pharmacy, laboratory technician, nursing, epidemiology, biostatistics, and health education. The final version of the questionnaire had a good indicator for reliability (as indicated by Alpha Cronbach test value of 0.809) (see Additional file 3).

The dependent variable of this study was overall clients' satisfaction. Out-patient service satisfaction is defined as meeting the perceived needs and the expectations of the client in relation to factors related to the health care provider and amenities. In order to measure the overall clients satisfaction, respondents were asked eight questions with likert five point scale (e.g. I am satisfied with overall cleanliness of the hospital compound) to describe their level of agreement in a five scale response. The 5-point liker scale response options, scored from 1 to 5 , were $1=$ strongly disagree, $2=$ disagree, $3=$ neutral, $4=$ agree, and $5=$ strongly agree. Subscale scores were obtained by summing item scores and dividing by the total number of items. If it was above or equal to the average, it would be indicative for good satisfaction.

Data were collected by literate and trained data collectors who were health professionals who are not working in the study site for 30 days with an average 14 exit interviews per day conducted in six confidential rooms using a structured and pre-tested questionnaire (see Additional file 3).

Binary logistic regression analysis was carried out to see the association between each independent variable with the outcome variable. Then, variables that showed significant associations at $\mathrm{P}$-value of 0.2 was included in a single model and multiple logistic regressions were performed to identify the most significant predictors. The $95 \% \mathrm{CI}$ and a P-value of 0.05 were used to assess the degree of statistical significance.

\section{Results \\ Socio-demographic characteristics of the participants}

Among the total samples $(n=423) 420$ adult patients' were interviewed, giving a response rate of $99.3 \%$.

Out of the total study subjects, 273 (65.5\%) were females. Two hundred fifteen $(51.2 \%)$ of the respondents were between the age group of 35-54 years. The mean age of the respondents was $39.8+$ (SD) (11.4) years, and $302(71.9 \%)$ of them were married. Concerning the religion and ethnicity of the respondents, the majority 341 (81.2\%) were orthodox and 235 (56\%) were Amhara respectively (Table 1).

\section{Outpatient service related characteristics of the participants}

One hundred sixty three $(38.6 \%)$ of the participants were satisfied with the location of each service area in the hospital. Respondents were asked about their level of satisfaction regarding the availability of enough waiting chairs and the spaciousness, brightness and airiness of the waiting room, only $80(19 \%)$ were satisfied. Concerning the toilet room out of the total 420 respondents only $355(84.5 \%)$ clients visited the toilet, of those only 88 (21\%) were satisfied with cleanliness and accessibility of the toilet.

One hundred thirty nine (33.1\%) of the participants were satisfied with the availability of drugs and supplies. One hundred thirty one (31.2\%) of the respondents were satisfied with the cares given to assure privacy at all service delivery points. Concerning the interaction with the health care providers and supportive staffs, about $163(38.8 \%)$ of the participants were satisfied with interaction they had with doctors/health officers at the outpatient department.

Concerning interaction with nurses, 182 (43.3\%) of the respondents were satisfied. Furthermore, from the total 358 participants who received laboratory service, $120(33.5 \%)$ of them were satisfied with the interaction of the laboratory staffs respectively. One hundred sixty six (39.5\%), and $71(19.9 \%)$ of the respondents were satisfied with the communication of the pharmacy staffs and card registration staffs. Generally, this study revealed that 197 (47\%) of the respondents were satisfied with the overall service provided in the outpatient department with median value 33 , mean value of 32.2 and standard deviation of \pm 4.1 (Table 2). 
Table 1 Socio-demographic characteristics of the study participant at Yekatit 12 Hospital Medical College, Addis Ababa June 2016

\begin{tabular}{|c|c|c|c|}
\hline $\mathrm{S} / \mathrm{N}$ & Socio-demographic variables & Frequency & Percent \\
\hline \multirow[t]{4}{*}{1} & Age & & \\
\hline & $\leq 34$ & 143 & 34 \\
\hline & $35-54$ & 215 & 51.2 \\
\hline & $\geq 55$ & 62 & 14.8 \\
\hline \multirow[t]{3}{*}{2} & Sex & & \\
\hline & Male & 145 & 34.5 \\
\hline & Female & 273 & 65.5 \\
\hline \multirow[t]{4}{*}{3} & Marital status & & \\
\hline & Married & 302 & 71.9 \\
\hline & Single & 81 & 19.3 \\
\hline & Others (divorced, widowed and cohabited) & 37 & 8.8 \\
\hline \multirow[t]{6}{*}{4} & Ethnicity & & \\
\hline & Amhara & 235 & 56 \\
\hline & Oromo & 83 & 19.7 \\
\hline & Guragie & 49 & 11.7 \\
\hline & Tigray & 23 & 5.5 \\
\hline & Others (Wolita, Hadiya, kenbata, yem) & 30 & 7.1 \\
\hline \multirow[t]{5}{*}{5} & Religion & & \\
\hline & Orthodox & 341 & 81.2 \\
\hline & Muslim & 44 & 10.5 \\
\hline & Protestant & 24 & 5.7 \\
\hline & Catholic & 14 & 3.3 \\
\hline \multirow[t]{6}{*}{4} & Educational status & & \\
\hline & Illiterate & 16 & 3.8 \\
\hline & Read and write & 17 & 4 \\
\hline & Grade 1-6 & 92 & 21.9 \\
\hline & Grade 7-12 & 151 & 36 \\
\hline & Diploma and above & 144 & 34.3 \\
\hline \multirow[t]{8}{*}{5} & Occupation & & \\
\hline & House wife & 161 & 38.3 \\
\hline & Merchant & 82 & 19.5 \\
\hline & Government employee & 58 & 13.8 \\
\hline & No job & 55 & 13.1 \\
\hline & Student & 33 & 7.9 \\
\hline & Retire & 20 & 4.8 \\
\hline & Farmer & 11 & 2.6 \\
\hline \multirow[t]{3}{*}{6} & Income & & \\
\hline & $<1500$ & 247 & 58.8 \\
\hline & $\geq 1500$ & 173 & 41.2 \\
\hline \multirow[t]{4}{*}{7} & Payment status (Did you pay money for the ser & & \\
\hline & Paying & 271 & 64.5 \\
\hline & Free & 124 & 29.5 \\
\hline & Credit & 25 & 6 \\
\hline \multirow[t]{3}{*}{8} & Did you consider the outpatient visit is too exp & & \\
\hline & Yes & 164 & 55.4 \\
\hline & No & 132 & 44.6 \\
\hline \multirow[t]{3}{*}{9} & Type of visit & & \\
\hline & Repeat & 374 & 89 \\
\hline & New & 89 & 11 \\
\hline
\end{tabular}

Table 2 Outpatient service related characteristics of the study participant at Yekatit 12 Hospital Medical College, Addis Ababa June 2016

\begin{tabular}{|c|c|c|c|}
\hline $\mathrm{S} / \mathrm{n}$ & Variables & Frequency & Percent \\
\hline \multirow[t]{3}{*}{1} & \multicolumn{3}{|c|}{ Sign and direction indicators were available to ease ways } \\
\hline & Yes & 163 & 38.6 \\
\hline & No & 257 & 61.2 \\
\hline \multirow[t]{3}{*}{2} & \multicolumn{3}{|l|}{ Over all comfort of waiting area of services } \\
\hline & Yes & 80 & 19 \\
\hline & No & 340 & 81 \\
\hline \multirow[t]{3}{*}{3} & \multicolumn{3}{|l|}{ Have got all ordered of prescribed drugs } \\
\hline & Yes & 139 & 33.1 \\
\hline & No & 281 & 66.9 \\
\hline \multirow[t]{3}{*}{4} & \multicolumn{3}{|l|}{ Accessibility of the toilet } \\
\hline & Yes & 88 & 21 \\
\hline & No & 340 & 81 \\
\hline \multirow[t]{3}{*}{4} & \multicolumn{3}{|l|}{ Cleanliness of the toilet } \\
\hline & Yes & 88 & 21 \\
\hline & No & 332 & 79 \\
\hline \multirow[t]{3}{*}{5} & \multicolumn{3}{|l|}{ Privacy maintained } \\
\hline & Yes & 131 & 33.2 \\
\hline & No & 289 & 68.8 \\
\hline \multirow[t]{3}{*}{6} & \multicolumn{3}{|l|}{ Interaction with doctors } \\
\hline & Good & 163 & 38.8 \\
\hline & Bad & 257 & 61.2 \\
\hline \multirow[t]{3}{*}{7} & \multicolumn{3}{|l|}{ Interaction with registration card } \\
\hline & Good & 71 & 16.9 \\
\hline & Bad & 349 & 83.1 \\
\hline \multirow[t]{3}{*}{8} & \multicolumn{3}{|l|}{ Interaction with nurses } \\
\hline & Good & 182 & 43.3 \\
\hline & Bad & 238 & 56.7 \\
\hline \multirow[t]{3}{*}{9} & \multicolumn{3}{|l|}{ Interaction with pharmacy } \\
\hline & Good & 166 & 39.5 \\
\hline & Bad & 254 & 60.5 \\
\hline \multirow[t]{3}{*}{10} & \multicolumn{3}{|l|}{ Interaction with laboratory } \\
\hline & Good & 120 & 33.5 \\
\hline & Bad & 238 & 66.5 \\
\hline \multirow[t]{3}{*}{11} & \multicolumn{3}{|l|}{ Overall level of satisfaction } \\
\hline & Satisfied & 197 & 47 \\
\hline & Dissatisfied & 223 & 53 \\
\hline
\end{tabular}

\section{Association between the level of satisfaction and selected variables}

Binary logistic regression was conducted using bivariate analysis for socio-demographic variables, and outpatient service related variables. Those variables with $\mathrm{P}$-values less than 0.2 at bi-variate analysis were included in multivariable analysis. In multivariable analysis, factors that remained statistically significant with patient satisfaction were availability of direction indicators (AOR 1.2, 95\% CI 1.01-2.43), privacy 
respected during consultation (AOR 2.9, 95\% CI 2.33, 3.76 ), cleanliness of the toilet (AOR 0.79, 95\% CI $0.43,0.99)$, availability of prescribed drugs in hospital pharmacy (AOR 1.9, 95\% CI 1.12-2.88), and interaction with registration room workers (AOR 5.3, 95\% CI 2.68-5.39 (Table 3).

Table 3 Association patients level of satisfaction with the selected variables in outpatient department of Yekatit 12 hospital medical colleges Addis Ababa, June 2016

\begin{tabular}{|c|c|c|c|c|}
\hline \multirow[t]{2}{*}{ Variables } & \multicolumn{2}{|c|}{ Level of satisfaction } & \multirow[t]{2}{*}{ Crude OR $(95 \% \mathrm{Cl})$} & \multirow[t]{2}{*}{ Adjusted OR $(95 \% \mathrm{Cl})$} \\
\hline & Dissatisfied & Satisfied & & \\
\hline \multicolumn{5}{|l|}{ Sex } \\
\hline Male & 84 & 139 & $0.8(0.52,1.17)^{*}$ & $1.2(0.78,1.83)$ \\
\hline Female & 63 & 134 & 1 & 1 \\
\hline \multicolumn{5}{|l|}{ Age } \\
\hline$\leq 34$ & 77 & 66 & $0.9(0.50,1.66)$ & $0.2(0.07,0.56)$ \\
\hline $35-54$ & 114 & 101 & $0.9(0.54,1.66)$ & $1.2(0.45,3.10)$ \\
\hline$\geq 55$ & 32 & 30 & 1 & 1 \\
\hline \multicolumn{5}{|c|}{ Family monthly income } \\
\hline$<1500$ & 205 & 144 & $0.9(0.58,1.27)$ & \\
\hline$\geq 1500$ & 88 & 85 & 1 & \\
\hline \multicolumn{5}{|l|}{ Payment status } \\
\hline Paying & 144 & 127 & $1.9(0.78,4.49)^{*}$ & $0.4(0.18,1.11)$ \\
\hline Free & 62 & 62 & $2.1(0.85,5.39)^{*}$ & $0.4(0.14,1.01)$ \\
\hline Credit & 17 & 8 & 1 & 1 \\
\hline \multicolumn{5}{|c|}{ Sign and direction indicators were available to ease ways } \\
\hline Yes & 106 & 57 & $0.7(0.11,0.96)^{*}$ & $1.2(1.01,2.43)^{* *}$ \\
\hline No & 202 & 55 & 1 & \\
\hline \multicolumn{5}{|c|}{ Privacy maintained during consultation } \\
\hline Yes & 31 & 100 & $2.6(2.11,3.32)^{*}$ & $2.9(2.33,3.76)^{* *}$ \\
\hline No & 201 & 88 & 1 & \\
\hline \multicolumn{5}{|c|}{ Cleanliness of the toilet } \\
\hline Yes & 39 & 49 & $0.59(0.37,0.97)$ & $0.79(0.43,0.99)^{* *}$ \\
\hline No & 300 & 32 & 1 & 1 \\
\hline \multicolumn{5}{|c|}{ Have got all ordered of prescribed drugs } \\
\hline Yes & 49 & 90 & $1.3(1.12,1.89)^{*}$ & $1.9(1.12,2.88)^{* *}$ \\
\hline No & 230 & 52 & 1 & 1 \\
\hline \multicolumn{5}{|c|}{ Interaction with $\mathrm{Dr} . / \mathrm{HO}$} \\
\hline Bad & 74 & 183 & $1.6(1.02,3.93)^{*}$ & $2.8(1.74,4.96)$ \\
\hline Good & 55 & 108 & 1 & 1 \\
\hline \multicolumn{5}{|c|}{ Interaction with nurse } \\
\hline Bad & 145 & 93 & $0.5(0.32,0.71)^{*}$ & $1.9(1.16,3.06)$ \\
\hline Good & 78 & 104 & 1 & 1 \\
\hline \multicolumn{5}{|l|}{ Interaction with lab } \\
\hline Bad interaction & 106 & 87 & $0.8(0.52,1.20)^{*}$ & $7(2.71,18.11)$ \\
\hline Good interaction & 81 & 84 & 1 & 1 \\
\hline \multicolumn{5}{|c|}{ Interaction with pharmacy } \\
\hline Bad & 201 & 53 & $0.8(0.51,1.11)^{*}$ & $0.6(0.34,0.95)$ \\
\hline Good & 81 & 85 & 1 & 1 \\
\hline \multicolumn{5}{|c|}{ Interaction with registration } \\
\hline Bad & 205 & 144 & $0.2(0.13,0.42)^{*}$ & $5.3(2.68,5.39)^{* *}$ \\
\hline Good & 18 & 53 & 1 & 1 \\
\hline
\end{tabular}

NB * statistically significant as the $P$ value is $<0.2$ for crude $O R$

** Statistically significant as $P$ value is $<0.05$ for adjusted $O R$ 


\section{Discussion}

This study showed that the overall satisfaction level of the outpatient services provided at Yekatit 12 Hospital Medical College (Y12HMC) was $47 \%$ at $95 \%$ CI $(42.5,51.7 \%)$.

This result is similar with the study done in Molango Hospital Uganda and Wolita Sodo University Teaching Hospital $[6,10]$. The present study suggested that overall satisfaction level report is low compared to the report of the studies conducted in, Bahirdar Felege Hiwot Referral Hospital, and Hawassa University Teaching Hospital, which showed 52.8 and $80.1 \%$ respectively [3, 10, 11]. Concerning the privacy, almost $88 \%$ of the participants did not have private consultation.

Furthermore, the regression analysis revealed that private consultation increased satisfaction by $97.1 \%$ at $95 \%$ CI $2.9(2.33,3.76)$. This is similar with a study conducted in the University of Gondar Referral and Teaching Hospital, Ethiopia [12]. However, this is extremely higher compared with other studies conducted in Felegehiwot Referral Hospital, North West Ethiopia (26\%) [11], Hawasa University Teaching Hospital 18.6\% [3], WolaitaSodo University Teaching Hospital, Southern Ethiopia $20 \%$ [10]. This difference might be due to the difference in the study areas.

According to the study conducted in India, easy accessibility and a good signage system for the OPD services provide a good image for the hospital [7]. However the researchers revealed that there was a statistically significant association between the absence and presence of direction sign against client satisfaction. The presence of signing direction increased satisfaction by $98.8 \%$. This finding was consistent with the previous study conducted in Bahirdar Ethiopia in which $74 \%$ of the participants were dissatisfied due to the absence of signing direction [11].

Pertaining to the cleanliness of the toilet, availability of clean toilet increased patient satisfaction by $79 \%$ at $95 \%$ CI $0.79(0.43,0.99)$. This is similar with the study done in Wolita-Sodo University Teaching Hospital [10], and the Felege-Hiwot Hospital Bahirdar, Ethiopia in which 62\% of the participants were dissatisfied due to luck of clean toilet [11].

Regarding the availability of drugs and supplies in the hospital, there was a significant association between the availability of drugs and overall level of satisfaction (AOR $1.9,95 \%$ CI 1.12-2.88). This is similar with the study conducted at private wing of Felegehiwot Hospital, Bahirdar and Hawassa University Teaching Hospital $[3,11]$.

\section{Conclusion}

The overall client satisfaction in Yekatit 12 Hospital Medical College was $47 \%$ at $95 \%$ CI $(42.5,51.7 \%)$ which was low as compared to different studies in Ethiopia and outside Ethiopia. High proportions of patients were dissatisfied with patient satisfaction measuring items. In order to gain better views of the field and produce more meaningful result, further study should be conducted with broader scope using comparative studies.

\section{Limitation}

The finding of this study is interpreted in light of several limitations. The cross-sectional design gives only a snap shot of events. Social desirability bias is also likely in this study as the respondents were interviewed in the compound of the health facility.

\section{Additional files}

Additional file 1. Population.

Additional file 2. Sample size determination and sampling procedure. Additional file 3. Data collection.

\section{Abbreviation}

Y12HMC: Yekatit 12 Hospital Medical College.

\section{Authors' contributions}

TTB involved in designing of the study, data collection, data analysis, drafting and critically reviewing the manuscript. Likewise, GEB, YSY and TZL involved in designing of the study, analysis of the data and critically reviewing the manuscript. All authors read and approved the final manuscript.

\section{Author details}

${ }^{1}$ Department of Public Health, College of Medicine, Yekatit 12 Hospitals, Addis Ababa, Ethiopia. ${ }^{2}$ Department of Preventive Medicine, School of Public Health, Addis Ababa University, Addis Ababa, Ethiopia.

\section{Acknowledgements}

The authors would like to thank Yekatit 12 Hospital Medical College for funding this study. The researchers would also sincerely thank the study participants for their participation in the study.

\section{Competing interests}

The authors declare that they have no competing interests.

\section{Availability of data and materials}

The finding of this study is generated from the data collected and analyzed based on the stated methods and materials. All the data are already found in the manuscript and there are additional files. See the additional files.

\section{Consent for publication}

Consent to publish is not applicable for this manuscript because there is no individual data details like images or videos.

\section{Ethics approval and consent to participate}

The study protocol was performed in accordance with the ethics principles. Ethical approval was obtained from the institutional review board of Yekatit 12 Hospital Medical College. The authors obtained written informed consent from all participants.

Funding

This study was funded by Yekatit 12 Hospital Medical College, Addis Ababa, Ethiopia. 


\section{Publisher's Note}

Springer Nature remains neutral with regard to jurisdictional claims in published maps and institutional affiliations.

Received: 20 October 2017 Accepted: 13 July 2018

Published online: 27 July 2018

\section{References}

1. Wissow LS, Tegegn T, Asheber K, McNabb M, Weldegebreal T, Jerene D, Ruff A. Collaboratively reframing mental health for integration of HIV care in Ethiopia. Health Policy Plan. 2015;30:791-803.

2. Donabedian A. The quality of care. How can it be assessed? J Am Med Assoc. 1988;260:1743-8

3. Asefa A, Kassa A, Dessalegn M. Patient satisfaction with outpatient health services in Hawassa University Teaching Hospital, Southern Ethiopia. J Public Health Epidemiol. 2014;6(2):101-10.

4. Al-Abri R, Al-Balush A. Patient satisfaction survey as a tool towards quality improvement. Oman Med J. 2014;29(1):3-7.

5. Elbireer AM, Opio AA, Brough RL, Jackson JB, Manabe YC. Strengthening public laboratory service in Sub-Saharan Africa: Uganda case study. Lab Med. 2011:42(12):719-25.
6. Nabbuye-Sekandi J, Makumbi FE, Kasangaki A, Kizza IB, Tugumisirize J, Nshimye E, Mbabali S, Peters DH. Patient satisfaction with services in outpatient clinics at Mulago hospital, Uganda. Int I Qual Health Care. 2011;23(5):516-23.

7. Mohd SLCA, Chakravarty BA. Patient satisfaction with services of the outpatient department. Med J Armed Forces India. 2014;70:237-42.

8. Mosadeghrad A. Factors influencing healthcare service quality. Int J Health Policy Manag. 2014;3:77-89.

9. Adamu $\mathrm{H}$, Oche MO. Patient satisfaction with services at a general outpatient clinic of a tertiary hospital in Nigeria. Br J Med Med Res. 2014;4(11):2181-202

10. Sagaro GG, Yalew AW, Koyira MM. Patients' satisfaction and associated factors among outpatient Department at Wolaita Sodo University Teaching Hospital, Southern Ethiopia: a cross sectional study. Sci J Clin Med. 2015;4(5):109-16.

11. Ambelie YA, Demssie AF, Gebregziabher MG. Patients'satisfaction and associated factors among private wing patients at Bahirdar Felege Hiwot Referral Hospital, North West Ethiopia. Sci J Public Health. 2014;2(5):417-23.

12. Gebremedhn EG, Lemma GF. Patient satisfaction with the perioperative surgical services and associated factors at a University Referral and Teaching Hospital, a cross-sectional study. Pan Afr Med J. 2014;2017:27.
Ready to submit your research? Choose BMC and benefit from:

- fast, convenient online submission

- thorough peer review by experienced researchers in your field

- rapid publication on acceptance

- support for research data, including large and complex data types

- gold Open Access which fosters wider collaboration and increased citations

- maximum visibility for your research: over $100 \mathrm{M}$ website views per year

At BMC, research is always in progress.

Learn more biomedcentral.com/submissions 